\title{
AUTISMO: UM ESTUDO DE HABILIDADES COMUNICATIVAS EM CRIANÇAS
}

\section{Autism: a study on communicative abilities in children}

\author{
Lílian Dantas Campelo ${ }^{(1)}$, Jonia Alves Lucena ${ }^{(2)}$, Cynthia Nascimento de Lima ${ }^{(3)}$, \\ Helane Mariza Machado de Araújo ${ }^{(4)}$, Larissa Gomes de Oliveira Viana ${ }^{(5)}$, \\ Mariana Martins Lira Veloso ${ }^{(6)}$, Priscila Izabela Freitas de Barros Correia ${ }^{(7)}$, Lílian Ferreira Muniz ${ }^{(8)}$
}

\begin{abstract}
RESUMO
Objetivo: analisar as habilidades comunicativas verbais e não-verbais de crianças autistas. Métodos: foram selecionadas seis crianças com o diagnóstico de atraso de linguagem secundário a autismo, submetidas à terapia fonoaudiológica em uma clínica escola de uma universidade privada da cidade do Recife. As crianças foram observadas em duas sessões de terapia, que foram gravadas em fita VHS para posterior análise e discussão. A análise foi baseada no uso do protocolo de observação pertencente ao ABFW, que contempla os meios e funções comunicativas. Resultados: em detrimento dos meios vocais e verbais, o meio gestual apareceu com maior frequência nos atos comunicativos. Os gestos, mesmo constituindo uma forma de comunicação não verbal, demonstraram, muitas vezes, expressar intenções dos sujeitos. Com relação às funções comunicativas, pôde-se concluir que houve uma grande variedade das mesmas, porém, entre as vinte funções investigadas, apenas poucas se destacaram. Entre elas, apareceram, predominantemente, as funções não-focalizadas, protesto, exploratória e reativa. Conclusão: foi possível verificar que as crianças investigadas utilizam formas funcionais de comunicação nos diferentes contextos situacionais, entre as habilidades verbais e não-verbais, aspectos considerados essenciais para a proposição de recursos na intervenção fonoaudiológica.
\end{abstract}

DESCRITORES: Linguagem; Transtorno Autístico; Fonoterapia

(1) Fonoaudióloga; Associação de Proteção à Maternidade e da Infância da Vitória de Santo Antão, APAMI, Santo Antão, PE; Pós-Graduada em Linguagem pela Universidade Católica de Pernambuco.

(2) Fonoaudióloga; Professora Adjunta da Universidade Católica de Pernambuco, UNICAP, Recife, PE; Doutora em Psicologia Cognitiva.

(3) Fonoaudióloga; Universidade Católica de Pernambuco, UNICAP, Recife, PE.

(4) Fonoaudióloga; Clínica Integrada Médico-odontológica, MA; Pós-Graduada em Motricidade Oral com enfoque em Disfagia pela Faculdade Integrada do Recife.

(5) Fonoaudióloga; São Lourenço da Mata, PE; Pós-Graduada em Fonoaudiologia Hospitalar pela Faculdade Estácio de Sá.

(6) Fonoaudióloga; Centro Psicopedagógico de Atividades Integradas, Recife, PE.

(7) Fonoaudióloga; Núcleo Ortopostural de Recife, PE; PósGraduada em Motricidade Oral com enfoque em Disfagia pela Faculdade Integrada do Recife.

(8) Fonoaudióloga; Professora Assistente da Universidade Católica de Pernambuco, UNICAP, Recife, PE; Doutora em Psicologia Cognitiva pela Universidade Federal de Pernambuco.

Conflito de interesses: inexistente

\section{INTRODUÇÃO}

O autismo infantil é considerado um distúrbio global do desenvolvimento que atinge a linguagem, a cognição e a interação social. Segundo a Organização Mundial de Saúde (OMS), na classificação internacional das doenças, o autismo é uma síndrome presente desde o nascimento, que se manifesta antes dos 30 meses, apresentando como características respostas anormais a estímulos auditivos ou visuais, como também dificuldades na compreensão da linguagem ${ }^{1}$. Algumas características de crianças autistas são enumeradas e podem ser utilizadas como critério de diagnóstico: dificuldades de relacionamento no início da vida; atraso no desenvolvimento da linguagem, envolvendo inversão pronominal, ecolalia, comportamento obsessivo e uso ritualístico da linguagem; repertório restrito de atividades e interesses, com desejo obsessivo pela manutenção da mesmice; desenvolvimento 
intelectual normal, com memória imediata excelente; desenvolvimento físico normal ${ }^{1,2}$.

$\mathrm{Na}$ verdade, o conceito atual de autismo envolve discussões que estão ligadas às diversas formas de pensamento, associadas à compreensão das alterações de relacionamento, afetividade ou comportamento. Entretanto, independente de qualquer abordagem conceitual, hipótese etiológica ou critério de diagnóstico, a linguagem sempre representa um aspecto fundamental desse quadro ${ }^{3-7}$. Diversas pesquisas associam as alterações na linguagem às causas do autismo infantil, quer seja como elemento desencadeador, quer como um aspecto afetado pelas mesmas desordens que o causam. Além disso, a linguagem também está ligada ao prognóstico desse transtorno infantil $1,8-10$.

As maiores dificuldades de linguagem enfrentadas por crianças com autismo são relacionadas aos aspectos pragmáticos e à estruturação de narrativas. Limitações de compreensão sobre como as pessoas usam a linguagem para obter algo e na interpretação de narrativas, impedem o sujeito autista de compreender, enunciar e manter uma conversação ${ }^{8,9,11-13}$. A teoria pragmática envolve os aspectos funcionais da linguagem, investigando as reações ou os efeitos de uma determinada emissão no ambiente ou no interlocutor, levando-se em conta tanto a linguagem verbal como não-verbal, os aspectos sociais e ambientais, ou seja, a relação entre a linguagem e o contexto 1,9,14,15.

A partir do momento em que a linguagem passa a ser vista não só como um código ou conjunto de regras gramaticais, mas também como atividade dialógica e cognitiva, é possível investigá-las em crianças com limitação ou ausência de linguagem, como no caso de algumas crianças autistas. Essa concepção de linguagem amplia o universo de investigação, na medida em que inclui os comportamentos não verbais no fenômeno da linguagem. A avaliação observacional, por exemplo, possibilitará obter dados qualitativos sobre os possíveis transtornos no desenvolvimento da linguagem, na medida em que não se preocupa com o número de respostas corretas ou incorretas da criança, mas com o funcionamento da linguagem. A partir dessa forma de avaliação, é possível se obter dados menos artificiais, ou seja, dados mais condizentes com a realidade comunicativo-linguística do cliente ${ }^{1,14}$.

Para a determinação do perfil comunicativo de crianças autistas, foi elaborado um protocolo de observação ${ }^{16}$ que envolve a identificação de 20 categorias funcionais. De acordo com esta proposta, os atos comunicativos começam quando a interação adulto-criança, criança-adulto, ou criançaobjeto é iniciada e termina quando o foco de atenção muda ou há uma troca de turno; a melhor situação de coleta de dados é a de linguagem espontânea. Quanto ao meio comunicativo utilizado, os atos comunicativos são divididos em: verbais (VE), que envolvem pelo menos $75 \%$ dos fonemas da língua; vocais (VO), que envolve todas as outras emissões; e gestuais (GE) que envolve os movimentos do corpo e do rosto. É comum as crianças autistas utilizarem mais comunicação gestual, menos verbal e poucas vocalizações, de acordo com estudos que analisam aspectos funcionais da comunicação terapeuta - paciente na terapia de linguagem de crianças autistas ${ }^{16,17}$

É interessante comentar que no trabalho com crianças autistas, o fonoaudiólogo deve ter em mente que se trata de um quadro clínico objeto de contradições e frequentes mudanças na sua descrição e categorização. O olhar do fonoaudiólogo deve extrapolar os limites dos meros sintomas apresentados pelos indivíduos, buscando-se sentido e interpretação. A linguagem, por sua vez, deve ser concebida em seu sentido mais amplo, ou seja, como instrumento da ação e interação da criança sobre o ambiente e sobre os outros. Ressalte-se que a abordagem teórica aqui adotada concebe a linguagem como elemento nuclear do estudo da comunicação. A partir da compreensão mais aprofundada sobre a linguagem, torna-se possível contribuir para a atuação fonoaudiológica junto a estas crianças, fortalecendo outras propostas diversas de estudos na área ${ }^{18}$ que já buscaram determinar o perfil funcional da comunicação de crianças e adolescentes com diagnósticos incluídos no espectro autístico. Sob esta perspectiva, esta pesquisa busca analisar as habilidades comunicativas verbais e não-verbais de crianças autistas.

\section{MÉTODOS}

Este estudo caracteriza-se como exploratório e descritivo. A coleta de dados foi realizada em uma clínica escola da cidade do Recife. Foram selecionadas para fazer parte da amostra crianças com atraso de linguagem, encaminhadas por psiquiatras com diagnóstico de transtorno autista, de acordo com o DSM-IV e a CID-10. Todas as crianças eram do sexo masculino, tinham idade entre quatro e 10 anos, estavam em acompanhamento fonoaudiológico e frequentavam escolas da rede pública de ensino, em turmas da Educação Infantil.

Inicialmente, o estudo foi apresentado aos pais e/ou responsáveis pelas crianças selecionadas para a pesquisa. Aqueles que permitiram a participação das crianças assinaram o Termo de Consentimento Livre e Esclarecido.

Posteriormente, cada criança foi observada, individualmente, em duas sessões de atendimento na 
clinica-escola, cada uma com 30 minutos de duração, com o objetivo de identificar as habilidades comunicativas. As sessões fonoaudiológicas foram gravadas em fita VHS para análise e discussão. Tal procedimento de coleta também já foi utilizado em outros estudos ${ }^{19}$.

Após análise das gravações das sessões de terapia fonoaudiológica dos seis sujeitos, foi realizada uma análise de toda e qualquer forma de linguagem utilizada por esses sujeitos (verbal ou não verbal), através da transcrição de atos comunicativos. A proposta adotada para este trabalho considera o ato comunicativo como unidade mínima de análise, que começa quando a interação adultocriança, criança-adulto ou criança-objeto é iniciada, terminando quando o foco de análise da criança muda ou há troca de turno ${ }^{15,16}$. Tal modelo é comumente proposto em estudos que tem como alvo a avaliação de aspectos da pragmática em crianças com alterações no desenvolvimento de linguagem $^{20}$.

Os aspectos envolvidos na análise foram: o meio comunicativo (atos comunicativos divididos em verbais (VE) que envolvem pelo menos $75 \%$ dos fonemas da língua, vocais (VO) que são todas as outras emissões e gestuais $(G)$, que corresponde aos movimentos do corpo e do rosto); e funções comunicativas, que estão divididas em vinte categorias funcionais de acordo com o protocolo de observação (Figura 1).

A referida pesquisa foi apresentada e aprovada ao Comitê de Ética em Pesquisa, sendo devidamente aprovada sob número 079/2004. Os responsáveis pelos participantes da pesquisa tiveram devolutiva dos achados na pesquisa, através de encontros informativos, após apresentação do estudo.

Os resultados são aqui apresentados mediante a utilização de tabelas que representam dados percentuais e numéricos sobre meios e funções comunicativas registradas nos diferentes atos comunicativos. E, para ilustrar os diferentes atos comunicativos, no decorrer da discussão são utilizados 15 recortes de situações vivenciadas no contexto terapêutico entre terapeuta e criança. Em cada sequência de atos comunicativos, são apresentados aspectos da manifestação comunicativa das crianças, seja através do recurso verbal ou não-verbal.

$\mathrm{Na}$ apresentação das sequências de atos, as crianças são referidas através de abreviaturas, utilizando-se "C1" para a criança de número um, "C2" para a criança de número dois, e assim sucessivamente. Desta forma, fica preservada a identidade de cada um dos participantes.

\section{RESULTADOS}

A Tabela 1 apresenta os meios comunicativos usados pelas crianças no estudo. Como pode ser observado, entre os 726 (100\%) atos comunicativos, $527(72 \%)$ foram gestuais, $159(22 \%)$ vocais e $40(6 \%)$ verbais. Na Tabela 1, observa-se, ainda, que das seis crianças em estudo, todas apresentaram atos comunicativos por meios gestuais e vocais, porém apenas três apresentaram atos comunicativos por meios verbais.

$\mathrm{Na}$ Tabela 2 são apresentadas as funções comunicativas predominantes em cada criança estudada, destacando-se aquelas que apareceram com maior frequência (posição 1-P1). Observa-se que as funções comunicativas que predominaram foram não-focalizada (NF) e protesto (PR).

A Tabela 3 demonstra a análise que focaliza as funções que aconteceram com maior frequência, considerando o total de atos comunicativos das seis crianças, segundo o meio comunicativo. Do total de $726(100 \%)$ atos, $554(76 \%)$ foram incluídos entre as quatro funções comunicativas que mais apareceram nos seis sujeitos investigados. Foram elas: NF (não focalizada), PR (protesto), XP (exploratória) e RE (reativa). Assim, pode ser visto que há uma restrição em relação ao número de funções comunicativas por parte das crianças autistas.

\section{DISCUSSÃO}

No que diz respeito aos 726 (100\%) atos comunicativos analisados, destaca-se a predominância do meio gestual 527 (72\%) em detrimento do vocal $159(22 \%)$ e verbal 40 (6\%). Registrou-se, ainda, que todas as seis crianças avaliadas apresentaram atos comunicativos por meios gestuais e vocais, mas apenas três apresentaram atos comunicativos por meios verbais. Estes achados são semelhantes a resultados de estudos ${ }^{16,17,21}$ que também mostraram o caráter predominante do meio gestual, com menor número de vocalizações e verbalizações, nas crianças autistas estudadas.

Chama-se a atenção para o fato da ausência de comunicação verbal como sendo uma das características que pode estar presente na criança autista. A ausência dessa forma de comunicação seria diferente daquela do deficiente auditivo e de crianças com transtorno de comunicação expressivo, pois estas últimas conseguem manter boa interação social e utilizar forma eficiente os recursos gestuais, o que não aconteceria com a criança autista ${ }^{11,12}$.

Acredita-se que qualquer forma de comunicação utilizada pelas crianças autistas deve ser interpretada na clínica fonoaudiológica como recurso rico de expressão desses sujeitos no mundo. 


\begin{tabular}{|c|c|c|}
\hline PEDIDO DE OBJETO & $\mathrm{PO}$ & Atos ou emissões usados para solicitar um objeto concreto e desejável. \\
\hline PEDIDO DE AÇÃO & $\mathrm{PA}$ & $\begin{array}{l}\text { Atos ou emissões usados para solicitar ao outro que execute uma ação. } \\
\text { Inclui pedidos de ajuda e outras ações envolvendo outra pessoa, ou outra } \\
\text { pessoa e um objeto. }\end{array}$ \\
\hline PEDIDO DE ROTINA SOCIAL & OS & $\begin{array}{l}\text { Atos ou emissões usados para solicitar ao outro que inicie ou continue um } \\
\text { jogo de interação social. É um tipo especifico de pedido de ação } \\
\text { envolvendo uma interação. }\end{array}$ \\
\hline $\begin{array}{l}\text { PEDIDO DE } \\
\text { CONSENTIMENTO }\end{array}$ & PC & $\begin{array}{l}\text { Atos ou emissões usados para pedir o consentimento do outro para a } \\
\text { realização de uma ação. Envolve uma ação executada. }\end{array}$ \\
\hline PEDIDO DE INFORMAÇÃO & $\mathrm{PI}$ & $\begin{array}{l}\text { Atos ou emissões usados para solicitar informações sobre um objeto ou } \\
\text { evento. Inclui questões "wh" e outras emissões com contorno entoacional } \\
\text { de interrogação. }\end{array}$ \\
\hline PROTESTO & PR & $\begin{array}{l}\text { Atos ou emissões usados para interromper uma ação desejada. Inclui } \\
\text { oposição de resistência à ação do outro e rejeição de objeto oferecido. }\end{array}$ \\
\hline $\begin{array}{l}\text { RECONHECIMENTO DO } \\
\text { OUTRO }\end{array}$ & $\mathrm{RO}$ & $\begin{array}{l}\text { Atos ou emissões usados para obter a atenção do outro e para indicar o } \\
\text { reconhecimento de sua presença. Inclui cumprimentos, chamados, } \\
\text { marcadores de polidez e de tema. }\end{array}$ \\
\hline EXIBIÇÃO & $\mathrm{E}$ & $\begin{array}{l}\text { Atos usados para atrair a atenção para si. A ação inicial pode ser } \\
\text { acidental, e a criança repete-a quando percebe que isso atrai a atenção do } \\
\text { outro. }\end{array}$ \\
\hline COMENTÁRIO & C & $\begin{array}{l}\text { Atos ou emissões usados para dirigir a atenção do outro a um objeto ou } \\
\text { evento. Inclui apontar, mostrar, descrever, informar e nomear de forma } \\
\text { interativa. }\end{array}$ \\
\hline AUTO-REGULATÓRIO & AR & $\begin{array}{l}\text { Emissões usadas para controlar verbalmente sua própria ação. As } \\
\text { emissões precedem imediatamente ou co-ocorrem com o comportamento } \\
\text { motor. }\end{array}$ \\
\hline NOMEAÇÃO & $\mathrm{N}$ & $\begin{array}{l}\text { Atos ou emissões usados para focalizar sua própria atenção em um objeto } \\
\text { ou evento através da identificação do referente. }\end{array}$ \\
\hline PERFORMATIVO & $\mathrm{PE}$ & $\begin{array}{l}\text { Atos ou emissões usados em esquemas de ação familiares aplicados a } \\
\text { objetos. Inclui efeitos sonoros e vocalizações ritualizadas produzidas em } \\
\text { sincronia com o comportamento motor da criança. }\end{array}$ \\
\hline EXCLAMATIVA & EX & $\begin{array}{l}\text { Atos ou emissões que expressem uma reação emocional a um evento ou } \\
\text { situação. Inclui expressões de surpresa, prazer, frustração e } \\
\text { descontentamento, e sucede imediatamente um evento significativo. }\end{array}$ \\
\hline REATIVOS & $\mathrm{RE}$ & $\begin{array}{l}\text { Atos ou emissões produzidos enquanto a pessoa examina ou interage } \\
\text { com um objeto ou parte do corpo. Não há evidencia de intenção } \\
\text { comunicativa, mas o sujeito está focalizando atenção de intenção } \\
\text { comunicativa, mas o sujeito está focalizando atenção em um objeto/parte } \\
\text { do corpo e parece estar reagindo a isso. Pode servir a funções de treino } \\
\text { ou auto-estimulação. }\end{array}$ \\
\hline NÃO-FOCALIZADA & $\mathrm{NF}$ & $\begin{array}{l}\text { Atos ou emissões produzidos embora o sujeito não esteja focalizando sua } \\
\text { atenção em nenhum objeto ou pessoa. Não há evidencia de intenção } \\
\text { comunicativa. Pode servir a funções de treino ou auto-estimulação. }\end{array}$ \\
\hline JOGO & $\mathrm{J}$ & $\begin{array}{l}\text { Atos ou emissões que envolvem atividade organizada, mas auto-centrada. } \\
\text { Inclui reações circulares primárias. Pode servir a funções de treino ou } \\
\text { auto-estimulação. }\end{array}$ \\
\hline EXPLORATÓRIA & $\mathrm{XP}$ & $\begin{array}{l}\text { Atos que envolvem atividades de investigação de um objeto particular ou } \\
\text { parte do corpo ou vestimenta do outro. }\end{array}$ \\
\hline NARRATIVA & NA & $\begin{array}{l}\text { Atos ou emissões destinadas a relatar fatos reais ou imaginários. Pode } \\
\text { haver ou não atenção por parte do ouvinte. }\end{array}$ \\
\hline EXPRESSÃO DE PROTESTO & EP & $\begin{array}{l}\begin{array}{l}\text { Choro, manha, birra, ou outra manifestação de protesto não } \\
\text { necessariamente dirigida a objeto, evento ou pessoa. }\end{array} \\
\text { nanta }\end{array}$ \\
\hline JOGO COMPARTILHADO & $\mathrm{JC}$ & Atividade organizada compartilhada entre adulto e criança. \\
\hline
\end{tabular}

Figura 1 - (Fernandes, 2003, p. 76 a 78) 
Tabela 1 - Distribuição numérica e percentual dos meios comunicativos utilizados pelas crianças

\begin{tabular}{|c|c|c|c|c|c|c|c|c|c|c|c|c|c|c|}
\hline \multirow{2}{*}{ MEIO } & \multicolumn{2}{|c|}{ C1 } & \multicolumn{2}{|c|}{ C2 } & \multicolumn{2}{|c|}{ C3 } & \multicolumn{2}{|c|}{ C4 } & \multicolumn{2}{|c|}{ C5 } & \multicolumn{2}{|c|}{ C6 } & \multicolumn{2}{|c|}{ TOTAL } \\
\hline & $\mathbf{N}$ & $\%$ & $\mathrm{n}$ & $\%$ & $\mathrm{n}$ & $\%$ & $\mathbf{n}$ & $\%$ & $\mathrm{~N}$ & $\%$ & $\mathbf{N}$ & $\%$ & $\mathrm{n}$ & $\%$ \\
\hline VERBAL & 0 & $0 \%$ & 0 & $0 \%$ & 4 & $5 \%$ & 0 & $0 \%$ & 18 & $17 \%$ & 18 & $12 \%$ & 40 & $6 \%$ \\
\hline VOCAL & 13 & $21 \%$ & 56 & $23 \%$ & 15 & $20 \%$ & 15 & $18 \%$ & 21 & $19 \%$ & 39 & $26 \%$ & 159 & $22 \%$ \\
\hline GESTUAL & 50 & $79 \%$ & 188 & $77 \%$ & 57 & $75 \%$ & 70 & $82 \%$ & 69 & $64 \%$ & 93 & $62 \%$ & 527 & $72 \%$ \\
\hline TOTAL & 63 & $100 \%$ & 244 & $100 \%$ & 76 & $100 \%$ & 85 & $100 \%$ & 150 & $100 \%$ & $150 \%$ & $100 \%$ & 726 & $100 \%$ \\
\hline
\end{tabular}

LEGENDA

C1 CRIANÇA 1 C3 CRIANÇA 1 C5 CRIANÇA 1

C2 CRIANÇA 1 C4 CRIANÇA 1 C6 CRIANÇA 1

Tabela 2 - Distribuição numérica e percentual das funções comunicativas predominantes de cada criança

\begin{tabular}{c|cc|cc|cc|cc|c|c|c|c}
\hline & \multicolumn{2}{|c|}{ CRIANÇA 1 } & \multicolumn{2}{c|}{ CRIANÇA 2 } & \multicolumn{2}{c|}{ CRIANÇA 3 } & \multicolumn{2}{c|}{ CRIANÇA 4 } & \multicolumn{2}{c|}{ CRIANÇA 5 } & \multicolumn{2}{c}{ CRIANÇA 6 } \\
\hline P1 & NF & $36-57 \%$ & NF & $115-47 \%$ & NF & $16-20 \%$ & PR & $27-33 \%$ & PR & $51-47 \%$ & PR & $35-23 \%$ \\
P2 & PR & $8-13 \%$ & XP & $97-40 \%$ & RE & $14-18,5 \%$ & J & $19-22 \%$ & NF & $23-21 \%$ & NF & $32-21 \%$ \\
P3 & EP & $6-10 \%$ & PR & $10-4 \%$ & J & $12-16 \%$ & RE & $10-12 \%$ & RE & $14-13 \%$ & PE & $19-13 \%$ \\
P4 & PA & $6-10 \%$ & J & $9-4 \%$ & XP & $11-15 \%$ & NF & $6-7 \%$ & XP & $8-7,5 \%$ & XP & $16-10 \%$ \\
P5 & XP & $3-5 \%$ & PA & $4-1,5 \%$ & PR & $8-11 \%$ & PA & $5-6 \%$ & JC & $5-5 \%$ & N & $11-7 \%$ \\
P6 & RE & $2-2,5 \%$ & PO & $4-1,5 \%$ & N & $5-7 \%$ & JC & $5-6 \%$ & PO & $4-3,5 \%$ & JC & $10-6,5 \%$ \\
P7 & OS & $2-2,5 \%$ & OS & $3-1 \%$ & C & $4-5 \%$ & EP & $4-4,5 \%$ & PA & $1-1 \%$ & RE & $9-6 \%$ \\
P8 & $/$ & $/$ & JC & $2-1 \%$ & JC & $3-4 \%$ & PE & $4-4,5 \%$ & J & $1-1 \%$ & E & $5-3,5 \%$ \\
P9 & $/$ & $/$ & $/$ & $/$ & PE & $2-2,5 \%$ & XP & $3-3 \%$ & EX & $1-1 \%$ & RO & $4-3 \%$ \\
P10 & $/$ & $/$ & $/$ & $/$ & RO & $1-1 \%$ & PO & $1-1 \%$ & $/$ & $/$ & C & $3-2,5 \%$ \\
P11 & $/$ & $/$ & $/$ & $/$ & $/$ & $/$ & PS & $1-1 \%$ & $/$ & $/$ & EX & $2-1,5 \%$ \\
P12 & $/$ & $/$ & $/$ & $/$ & $/$ & $/$ & $/$ & $/$ & $/$ & $/$ & PA & $2-1,5 \%$ \\
P13 & $/$ & $/$ & $/$ & $/$ & $/$ & $/$ & $/$ & $/$ & $/$ & $/$ & PO & $1-0,75 \%$ \\
P14 & $/$ & $/$ & $/$ & $/$ & $/$ & $/$ & $/$ & $/$ & $/$ & $/$ & J & $1-0,75 \%$ \\
\hline
\end{tabular}

\section{LEGENDA}

PO PEDIDO DE OBJETO

PA PEDIDO DE AÇÃO

OS PEDIDO DE ROTINA SOCIAL

PC PEDIDO DE CONSENTIMENTO

PI PEDIDO DE INFORMAÇÃO

PR PROTESTO

RO RECONHECIMENTO DO OUTRO

E EXIBIÇÃO

C COMENTÁRIO

AR AUTO-REGULATÓRIO

$\begin{array}{llll}\text { N } & \text { NOMEAÇÃO } & \text { P1 } & \text { POSIÇÃO 1 } \\ \text { PE } & \text { PERFORMATIVO } & \text { P2 } & \text { POSIÇÃO 2 } \\ \text { EX } & \text { EXCLAMATIVA } & \text { P3 } & \text { POSIÇÃO 3 } \\ \text { RE } & \text { REATIVOS } & \ldots & \ldots \\ \text { NF } & \text { NÃO-FOCALIZADA } & & \\ \text { J } & \text { JOGO } & & \\ \text { XP } & \text { EXPLORATÓRIA } & & \\ \text { NA } & \text { NARRATIVA } & & \\ \text { EP } & \text { EXPRESSÃO DE PROTESTO } & & \\ \text { JC } & \text { JOGO COMPARTILHADO } & & \end{array}$

Tabela 3 - Distribuição numérica e percentual das funções comunicativas mais ocorridas nos seis sujeitos estudados, segundo meio comunicativo

\begin{tabular}{ccccccccccc}
\hline & \multicolumn{2}{c}{ NF } & \multicolumn{2}{c}{ PR } & \multicolumn{2}{c}{ XP } & \multicolumn{2}{c}{ RE } & \multicolumn{2}{c}{ TOTAL } \\
\cline { 2 - 12 } MEIO & $\mathbf{n}$ & $\%$ & $\mathbf{n}$ & $\%$ & $\mathbf{n}$ & $\%$ & $\mathbf{n}$ & $\%$ & $\mathbf{n}$ & $\%$ \\
\hline VERBAL & 7 & $3 \%$ & 16 & $12 \%$ & - & - & - & - & 23 & $\mathbf{4} \%$ \\
VOCAL & 69 & $30 \%$ & 34 & $24 \%$ & 17 & $12 \%$ & 16 & $32 \%$ & 136 & $\mathbf{2 5 \%}$ \\
GESTUAL & 151 & $67 \%$ & 89 & $64 \%$ & 121 & $88 \%$ & 34 & $68 \%$ & 395 & $\mathbf{7 1 \%}$ \\
TOTAL & $\mathbf{2 2 7}$ & $\mathbf{1 0 0} \%$ & $\mathbf{1 3 9}$ & $\mathbf{1 0 0} \%$ & $\mathbf{1 3 8}$ & $\mathbf{1 0 0} \%$ & $\mathbf{5 0}$ & $\mathbf{1 0 0} \%$ & $\mathbf{5 5 4}$ & $\mathbf{1 0 0 \%}$ \\
\hline
\end{tabular}

LEGENDA

NF FUNÇÃO NÃO FOCALIZADA

XP FUNÇÃO EXPLORATÓRIA
PR FUNČÃO PROTESTO RE FUNÇÃO REATIVA 
É relevante valorizar a linguagem da criança autista como um todo, atribuindo significados e sentidos, tanto aos aspectos da comunicação verbal como não-verbal, mais do que se preocupar, prioritariamente, com a fala propriamente dita. Portanto, se os gestos são uma forma encontrada pela criança autista para se comunicar, eles devem ser reinterpretados e ressignificados pelo fonoaudiólogo.

Ainda sobre a utilização de gestos, comenta-se que raramente são utilizados pela criança autista com finalidade comunicativa ${ }^{11}$. No entanto, constata-se, neste estudo, que, em algumas situações, os gestos têm intenção comunicativa, como pode ser constatado nas sequências de atos 1, 2 e 3, ilustradas a seguir. Nas sequências 1 e 2, sugerese que, através dos gestos, as crianças estudadas tinham a intenção de fazer com que a terapeuta realizasse uma ação desejada. $\mathrm{Na}$ sequência de atos 3, verifica-se a resistência da Criança 2 (C2) em calçar as sandálias, por saber que nesse momento acabaria a sessão de terapia e ela deveria ir embora.

\section{SEQUÊNCIA DE ATOS 1:}

C2 olha para a terapeuta, segura sua mão e a conduz para o armário. C2 faz com que a terapeuta coloque $o$ avião no armário, bate palmas e emite vocalizações. C2 segura novamente a mão da terapeuta para que o coloque no colo, a fim de que possa alcançar o armário com o objetivo de tentar pegar uma caixa que estava dentro dele e a terapeuta pede que ele pegue o avião.

\section{SEQUÊNCIA DE ATOS 2:}

Criança 5 (C5) tenta tirar a meia do pé, mas não consegue, então a terapeuta tira-a, depois mostra para C5. C5 olha a meia e depois olha para o pé esquerdo, que ainda está com meia, e a terapeuta tira sua meia.

\section{SEQUÊNCIA DE ATOS 3:}

A terapeuta chama C2 para calçar a sandália. C2 vai para o colchão e pula, olhando a terapeuta pegar a sandália. C2 senta no colchão, emite vocalizações, olha e pega a sandália. A terapeuta pergunta a C2 como calçar a sandália, C2 levanta-se e empurra com os pés as mesmas.

Quanto às funções comunicativas predominantes em cada criança estudada, foram destaque a não-focalizada (NF) e protesto (PR). A função não focalizada (NF), que corresponde aos atos ou emissões produzidos ${ }^{12,16}$, embora o sujeito não esteja focalizando sua atenção em nenhum objeto ou pessoa, prevalece em três crianças das seis estudadas (Criança1 - C1; Criança 2-C2; e Criança 3-C3).
Para Delinicolas e Young, dificuldades em manter a atenção são características de crianças com autismo, já que tem estreita relação com a capacidade de se relacionar socialmente ${ }^{22}$. Outros autores supõem, inclusive, que o uso estereotipado e rígido da linguagem serve como regulador da interação ${ }^{23}$.

Aqui, faz-se necessário chamar a atenção para o fato de que a fala ecolálica é alvo de discussões na literatura fonoaudiológica. Cabe destacar, entretanto, que os estudos mais recentes sobre a ecolalia procuram atribuir sentido a esta forma de comunicação. Pela heterogeneidade indefinível de falas consideradas ecolálicas, como é encontrado em diversos estudos, deve-se entender a ecolalia como um acontecimento que faz parte do todo de uma fala. A singularidade dos sujeitos e dos processos vividos por ele deve ser valorizada. A autora chama a atenção para a importância de uma nova "escuta", que resulta em novas perspectivas terapêuticas ${ }^{24}$.

Considera-se, então, que é, de fato, importante levar em conta as especificidades e particularidades dos sujeitos que estão por trás dessa fala, pois são essas diferenças que devem instigar o terapeuta à reflexão. Nas sequências de atos 4,5 e 6, respectivamente, ao verbalizar "AI XANDINHO", "NÃO RAPAZ! Ô XANDINHO" e "Ô RAPAZ", C5 teve a intenção de parar 0 ato da terapeuta. Supõe-se que, em algum momento, foi dito a C5 essa mesma expressão a fim de parar alguma atividade que o mesmo realizava.

\section{SEQUÊNCIA DE ATOS 4:}

A terapeuta tenta calçar a meia em C5 e este não deixa, batendo o pé na cama e gritando: "Al XANDINHO!”.

\section{SEQUÊNCIA DE ATOS 5:}

C5 fica agitado por não escutar o jogo que a terapeuta coloca no som, e começa a se balançar e mexer nas orelhas. Imediatamente a terapeuta desliga o som e C5 diz: "NÂO RAPAZ! Ô XANDINHO".

\section{SEQUÊNCIA DE ATOS 6:}

Terapeuta faz cócegas na barriga de C5 e esse se agita, bate as pernas na cama e diz: Ô RAPAZ!

Com relação à função de protesto (PR), que corresponde aos atos ou emissões usados para interromper uma ação indesejada, incluindo oposição de resistência a ação do outro e rejeição de objeto oferecido ${ }^{16}$, prevalece nos sujeitos de números 4 , 5 e 6.

A frequente ocorrência da função PR pode estar relacionada ao fato de que, segundo uma das características da criança autista é a resistência a mudanças. Assim, a forma encontrada pelas crian- 
ças autistas, em estudo, em se opor a algum fato executado pela terapeuta, realizava-se através da função comunicativa de protesto. Isto pode ser visto nas sequências de atos 7, 8 e 9 .

Na sequência de atos 7, por exemplo, C2 tenta impedir a terapeuta de guardar os brinquedos, já que C2 apresenta resistência a ação do outro, desejando, ele (C2) mesmo, realizar a ação. $\mathrm{Na}$ sequência de atos $8, C 5$, ao verbalizar "NÃO" e tomar a ambulância da terapeuta, interrompeu uma ação indesejada, opondo-se a ação da terapeuta. Na sequência 9, Criança 6 C6 apresenta rejeição do objeto oferecido, ao embaralhar os carros enfileirados pela terapeuta.

\section{SEQUÊNCIA DE ATOS 7:}

C2 observa a terapeuta colocar alguns brinquedos em um saco. C2 tenta pegar o saco da terapeuta, como não consegue, começa a pular pela sala, desviando o foco de atenção.

\section{SEQUÊNCIA DE ATOS 8:}

A terapeuta pega a ambulância das mãos de C5 e coloca no chão. C5 levanta para pegá-la, diz NÃO e volta para cama.

\section{SEQUÊNCIA DE ATOS 9:}

A terapeuta enfileira todos os carrinhos e C6 presta atenção, depois C6 embaralha todos os carrinhos.

A análise que focaliza as funções que aconteceram com maior frequência, considerando o total de atos comunicativos das seis crianças, segundo o meio comunicativo mostra que dos 726 (100\%) atos, $554(76 \%)$ foram incluídos entre as quatro funções comunicativas que mais apareceram nos seis sujeitos investigados: NF (não focalizada), PR (protesto), XP (exploratória) e RE (reativa). De acordo com estudo ${ }^{17}$, em terapia individual a função não-focalizada parece fazer-se mais presente. Tal constatação foi verificada neste estudo referido em que a autora analisou o perfil comunicativo de crianças com transtorno do espectro autístico, ao comparar diferentes propostas de intervenção de linguagem ${ }^{17}$.

Era de se esperar que as funções NF (Não focalizada) e PR (Protesto) aparecessem em destaque na análise geral das funções, considerando os 726 $(100 \%)$ atos comunicativos, uma vez que estas mesmas funções comunicativas apareceram como predominantes em cada sujeito estudado, individualmente. Verifica-se que não-focalizada (NF) apareceu na posição 1 (P1) com 151 (67\%) atos comunicativos gestuais. Quanto aos atos comunicativos vocais, estes somaram 69 (30\%), enquanto que os
$7(3 \%)$ demais atos foram verbais. Protesto (PR) apareceu na posição 2 (P2) com 89 (64\%) atos comunicativos gestuais, $34(24 \%)$ atos comunicativos vocais e $16(12 \%)$ atos comunicativos verbais.

As funções comunicativas exploratória (XP) e reativa (RE) também apareceram com frequência entre as funções, como pode ser visto na Tabela 3. Segundo estudo ${ }^{16}$, a XP é descrita como um ato que envolve atividades de investigação de um objeto particular ou de uma parte do corpo ou da vestimenta do outro, enquanto que a função comunicativa reativa (RE) corresponde às emissões produzidas enquanto a pessoa examina ou interage com um objeto ou com parte do corpo, parecendo reagir a isso. Nas crianças em estudo, a função exploratória (XP) está na posição 3 (P3) com 121 $(88 \%)$ atos comunicativos gestuais e $17(12 \%)$ atos comunicativos vocais e a reativa (RE) está na posição 4 (P4) com 34 (68\%) atos comunicativos gestuais e $16(32 \%)$ atos comunicativos vocais.

Supõe-se que o aparecimento dessas funções em P3 e P4 acontece pelo repertório restrito de atividades e interesses que essas crianças aprese$\operatorname{tam}^{2}$.

Nas sequências de atos 10, 11 e 12, exemplificam-se as funções $X P$, enquanto que na sequência $13,14,15$, aparecem as funções RE. Nas sequências 10,11 , e 12, as crianças observam um objeto em particular. Especificamente, na sequência 10, C5 investiga a chupeta; na sequência 11, o objeto examinado por C4 é a câmera filmadora; e, na sequência 12, a criança desperta interesse de investigação pelos carrinhos.

Nas três demais sequências de atos $(13,14 \mathrm{e}$ 15), os sujeitos parecem reagir durante a interação. No ato 13 C4 sorri (reação), após estimulação da terapeuta. No ato 14, C3, ao focalizar atenção no objeto (computador), reage a estímulos sonoros produzidos pelo mesmo. E no ato 15, C3, ao interagir com a terapeuta, reage com risos por causa da brincadeira com os animais.

\section{SEQUÊNCIA DE ATOS 10:}

C5 entra na sala de terapia, deita-se na cama e sua mãe Ihe dá a chupeta. C5 pega a chupeta, fica olhando e depois coloca na boca.

\section{SEQUÊNCIA DE ATOS 11:}

A terapeuta chama C4 para ir embora, mas ele C4 para na frente da câmera filmadora, coloca o dedo na boca e fica um bom tempo observando-a.

\section{SEQUÊNCIA DE ATOS 12:}

A terapeuta conversa com C6 dizendo que ele não pode cuspir e C6 fica analisando os carrinhos, desconsiderando o que diz a terapeuta. 


\section{SEQUÊNCIAS DE ATOS 13:}

A terapeuta pega um brinquedo e passa pelo corpo de C4, cantando "atirei o pau no gato" e C4 sorri.

\section{SEQUÊNCIAS DE ATOS 14:}

C3 está na frente do computador brincando com os animais. C3, ao clicar em cima do cavalo, ouvindo o som do mesmo, se assusta, corre para junto da terapeuta e depois sorri.

\section{SEQUÊNCIAS DE ATOS 15:}

A terapeuta pergunta a C3 qual o som que $O$ cachorro faz, em seguida a terapeuta faz a onomatopeia do cachorro. C3 ri e emite alguns sons.

Por fim, ressalta-se que, das 20 categorias de funções comunicativas já descritas ${ }^{16,18}$, apenas quatro não foram identificadas nas crianças investigadas, que são as funções auto-regulatória, pedido de consentimento, narração e pedido de informação.

Com relação às funções auto-regulatória e pedido de consentimento, o seu não aparecimento pode estar ligado ao fato de que essas funções representam uma atitude interativa que envolve basicamente a possibilidade de autocontrole, pois implica o adiamento da satisfação do desejo ou da necessidade ${ }^{16}$.

Já as funções de narração e de pedido de informação, possivelmente, não aparecem devido à dificuldade que as crianças autistas têm em manter conversas, já que estas possuem como características dificuldades de interagir com outras pessoas, assim como um comprometimento no desenvolvimento da linguagem ${ }^{22,23}$.
Acrescenta-se que as maiores dificuldades das crianças autistas estão relacionadas às questões pragmáticas e à produção de narrativas, já que há uma limitação de compreensão da forma como as pessoas utilizam a linguagem para obter algo e na própria interpretação de narrativas, impedindo o sujeito autista de compreender, enunciar e manter uma conversação ${ }^{9,11-13}$.

\section{CONCLUSÕES}

A pesquisa teve como objetivo analisar as habilidades comunicativas verbais e não-verbais de crianças autistas. Para tal, foi utilizado um modelo de análise que toma como base os atos comunicativos, identificando-se os meios e funções comunicativas.

Quanto aos meios comunicativos, foi observado que apareceram, com maior frequência, atos comunicativos por meio gestual, em detrimento dos meios vocais e verbais. No entanto, os gestos, mesmo constituindo uma forma de comunicação não verbal, demonstraram, muitas vezes, expressar intenções dos sujeitos. Com relação às funções comunicativas, pôde-se concluir que houve uma grande variedade das mesmas, porém, entre as vinte funções investigadas, apenas poucas se destacaram. Entre elas, apareceram, predominantemente, as funções não-focalizadas, protesto, exploratória e reativa.

\section{AGRADECIMENTOS}

Aos pacientes participantes deste estudo e seus familiares, pela disponibilidade em todo o processo de busca na coleta de dados. À UNICAP, pelo incentivo constate à pesquisa e formação profissional.

\begin{abstract}
Purpose: to evaluate the verbal and non-verbal communicative abilities in autist children. Methods: six children was selected with the diagnostic of language delay secondary to autism, submitted to speech therapy in a school-clinic of a University private from Recife. The children were monitored in therapy sessions, and these was stored in VHS tape for posterior analysis and discussion. The analysis was based on the use of ABFW observation protocol, which analyses the communicative means and functions. Results: among the acts, the gestures appeared with major predominance among the analyzed subjects. Regarding the communicative functions, we observed with major predominance: non-focused, protest, explorer and reactive. Conclusion: It was possible to verify that the studied children used functional communication forms in different situational contexts, verbal and non-verbal skills, aspects considered essential to the proposition of resources in speech therapy intervention.
\end{abstract}

KEYWORDS: Language; Autistic Disorder; Speech Therapy 


\section{REFERÊNCIAS}

1. Fernandes FDM. Sugestões de procedimentos terapêuticos de linguagem em distúrbios do espectro autístico. In: Limongi S, organizadora. Procedimentos terapêuticos em linguagem. Rio de Janeiro: Guanabara Koogan; 2003. p. 55-66.

2. Kanner L. Distúrbios autísticos do contato afetivo. [homepage na internet] Associação de Amigos do Autista: São Paulo. [acesso em 25 fev de 2006] Disponível em: URL: http://www.ama.org.br/html/ home.php.

3. Fernandes FDM. Resultados de terapia fonoaudiológica com adolescentes com diagnóstico inserido no espectro autístico. Pró-Fono. 2005; 17(1):67-76.

4. Cardoso C, Fernandes FDM. Relação entre os aspectos sócio cognitivos e perfil funcional da comunicação em um grupo de adolescentes do espectro autístico. Pró-Fono. 2006; 18(1):89-98.

5. Ziatas K, Durkin K, Pratt C. Differences in assertive speech acts produced by children with autism, Asperger syndrome, specific language impairment, and normal development. Develop Psychopathol. 2003; 15(1):73-94.

6. Fernandes FDM, Miilher LP. Relações entre a Autistic Behavior Checklist (ABC) e o perfil funcional da comunicação no espectro autístico. Pró-Fono. 2008; 20(2):111-6.

7. Luyster RJ, Kadlec MB, Carter A, Tager-Flusberg $\mathrm{H}$. Language assesssment and development in toddlers with autism spectrum disorders. J Autism Develop Dis. 2008; 38(8):1426-38.

8. Perissinoto J. Processo de evolução da criança com autismo. In: Perissinoto J, organizadora. Conhecimentos essenciais para atender bem a criança com autismo. São Paulo: Pulso; 2003. p. 23-7.

9. Cardoso C, Fernandes FDM. A comunicação de crianças do espectro autístico em atividades em grupo. Pró-Fono. 2004; 16(1):67-74.

10. Smith V, Mirenda P, Zaidman-Zait A. Predictors of expressive vocabulary growth in children with autism. J Speech Lang Hear Res. 2007; 50(1):149-60.

\section{DOI: 10.1590/S1516-18462009005000044}

RECEBIDO EM: 26/05/2008

ACEITO EM: 04/06/2009

Endereço para correspondência:

Jonia Alves Lucena

Rua Amapá, 27 ap. 1204

Recife - PE

CEP: $52050-390$

E-mail: jonialucena@ @erra.com.br
11. Perissinoto J. Linguagem da criança com autismo. In: Perissinoto $\mathrm{J}$, organizadora Conhecimentos essenciais para atender bem a criança com autismo. São Paulo: Pulso; 2003. p. 39-44.

12. Rutter M, Schopler E. Autism and pervasive developmental disorders: concepts and diagnostic issues. In: Schopler E, Mesibov GB, organizadores. Diagnosis and assessment in autism. New York: Plenum Press; 1988. p. 15-36.

13. Philofsky A, Fidler DJ, Hepburn S. Pragmatic language profiles of school-age children with autism spectrum disorders and Williams syndrome. Am J Speech Lang Pathol. 2007; 16(4):368-80.

14. Hage $S$. Avaliando a linguagem na ausência da oralidade: estudos psicolinguísticos. 2. ed. Bauru: Edusc; 2001. 95p.

15. Cardoso C, Fernandes FDM. Uso de funções comunicativas interpessoais e não interpessoais em crianças do espectro autístico. Pró-Fono. 2003; 15(3):279-86.

16. Fernandes F. Aspectos funcionais da comunicação terapeuta-paciente na terapia da linguagem de autistas. Pró-Fono. 1997; 9(2):11-6.

17. Fernandes FD. Perfil comunicativo, desempenho sociocognitivo, vocabulário e meta-representação em crianças com transtornos do espectro autístico. Pró-Fono. 2003; 15(3):267-78.

18. Miilher L, Fernandes F. Análise das funções comunicativas expressas por terapeutas e pacientes do espectro autístico. Pró-Fono. 2006; 18(3):239-48.

19. Lopes-Herrera SA, Almeida MA. O uso de habilidades comunicativas verbais para aumento da extensão de enunciados no autismo de alto funcionamento e na síndrome de Asperger. PróFono. 2008; 20(1):37-42.

20. Befi-Lopes DM, Cattoni DM, Almeida RC. Avaliação de aspectos da pragmática em crianças com alteração no desenvolvimento da linguagem. Pró-Fono. 2000; 12(2):39-47.

21. Smith IM, Bryson SE. Gesture imitation in autism: symbolic gestures and pantomimed object use. Cognitive Neuropsychol. 2007; 24(7):679-700. 22. Delinicolas EK, Young RL. Joint attention, language, social relating, and stereotypical behaviours in children with autistic disorder. Autism. 2007; 11(5):425-36.

23. Loveland KA, Landy S, Hughes S, Hall S, McEvoy R. Speech acts and the pragmatic deficits of autism. J Speech Hear Res. 1998; 31(4):593-604. 24. Lima ANF. A ecolalia como produção de linguagem: estudo de um caso no contexto fonoaudiológico. [monografia] Recife (PE): Universidade Católica de Pernambuco; 2004. 46p. 